\title{
DEMAND FORECASTING IN AN AUTOMOTIVE COMPANY: AN ARTIFICIAL NEURAL NETWORK APPROACH
}

\author{
Letizia Tebaldi $^{(a)}$, Sara Pindari ${ }^{(b)}$, Eleonora Bottani ${ }^{(c)}$ \\ (a), (b), (c) Department of Engineering and Architecture, University of Parma, Viale delle Scienze 181/A, 43124 Parma \\ (Italy) \\ (a) letizia.tebaldi@unipr.it, ${ }^{(b)}$ sara.pindari@studenti.unipr.it, ${ }^{(c)}$ eleonora.bottani@unipr.it
}

\begin{abstract}
This work proposes the development of two Artificial Neural Network (ANN) models for demand forecasting in the automotive industry. The networks are involved for predicting the demand of eighteen car components for a company based in the North of Italy. Statistical Package for Social Sciences (SPSS) was used as software for developing the ANNs, by setting the automatic architecture selection. The structure of the two ANN models is similar; they only differ for the partitioning of the historical data provided by the company itself respectively into training, testing and the optional holdout phases: in the first, which is the one returning the best result, data are simply assigned according to a pre-fixed percentage, while in the second a partitioning variable is introduced.
\end{abstract}

Keywords: Artificial Neural Network (ANN); demand forecasting; case study; automotive industry; SPSS.

\section{INTRODUCTION}

Whether the whole production will be employed, the out of stock (OOS) followed by loss of sales or a surplus will occur and many others, are among the main question marks affecting companies in almost any industry field. If the demand forecasting was an exact science, there would probably be no failures, problems, waste or dissatisfactions; but in a stochastic world the variability of the demand is an anchor which necessarily has to be taken into account and this creates a challenge because firms have to make operational decisions before this uncertainty is resolved (Jiang et al., 2016).

The demand forecasting is defined by Fradinata et al. (2014) as the process of using sales history of a determined product and projecting the demand in the future in order to schedule and support purchases, production, resources allocation, level of stocks, sales, workforce and many other items; accordingly, its estimated value is vitally important in business context. Moreover, the customer satisfaction is a direct consequence of an accurate demand forecasting process. Among the main benefits achievable through an accurate forecasting, surely on top fewer missed sales, followed by higher customer-service levels, lower working capital, more efficient manufacturing, less waste and spoilage, reduced effort and raw material/finished goods inventory (Myerholtz and Cafferey, 2014; Croxton et al., 2002).

Several tools can be involved in predicting the demand of a determined product or component, both quantitative (e.g. the renowned autoregressive and integrated moving average, better known as ARIMA, or the exponential smoothing) and qualitative (e.g. Delphi method or life-cycle analogy).

As complexity and dimensions of supply chains are always undergoing changes and development, traditional forecasting techniques such as the aforementioned methods are not always suitable to deal with difficulty and especially nonlinear nature of the problem (Laosiritaworn, 2011). According to that, more reliable and accurate tools were required and among these the Artificial Neural Networks (ANNs) have been widely used in the context of demand forecasting, since the Sixties.

ANNs are machine learning algorithms (Yucesan et al., 2017) aiming at solving classification, optimization, pattern recognition and forecasting problems (Hamzaçebi et al., 2017) by taking inspiration from the natural behaviour of neurons in the human brain. Their main peculiarity is that, just like neurons do, these networks learn from experience and examples, and are able to capture subtle functional relationships among input and output data even if these relationships are unknown or hard to describe (Zhang et al., 1998). To this end, they are firstly trained by providing a sample of input and related output so that they can identify the function connecting these data; secondly, the testing phase inspects whether the output obtained from a set of initial input by applying the model identified in the training phase is in line with the real output; thirdly the optional holdout step repeats the process for a new set of data for verification. The accuracy of findings is measured through the deviation between the output of the ANN and the real output value (i.e. the error).

Specifically, within the context of demand forecasting, input data for the ANN are those factors impacting and affecting the demand, which corresponds to the output. According to what has been said, the aim of this paper is to present two ANN models developed to predict the demand of car components for a company (for the sake 
of privacy the anonymity is respected, and in the following we will generally refer to Company A) operating in the automotive sector, based in the North of Italy. In particular, it produces racing cars by assembling components which can be either supplied or made in-house; typically, cars are directly sold to teams participating to worldwide championships, while for components the market is wider since also other companies or privates are reached.

The two models own the same structure, while they differ for the historical data division respectively into training, testing and the optional holdout phases.

Statistical Package for Social Sciences (SPSS) release 25 for Windows (IBM) was chosen as software for developing the ANNs and simulating the trend in demands.

For an exhaustive and current review of the relevant literature on the use of ANNs for demand forecasting problems see Bottani et al. (2019), demonstrating the versatility and the flexibility of the tool as it is proposed in different contexts. As far as the automotive sector, the only works in line with our specific topic are by Gonazález Vargas and Cortés (2017) and by Shahrabi et al., (2009), in both of which different forecasting methods, including the ANNs, are implemented and compared in predicting the demand of car spare-parts, respectively in Mexico and Iran. Indeed, this very limited number of studies is the reason why the choice fell on this specific industry field; moreover, the automobile supply chain is complicated because of the thousands of components and parts which makes it involving numerous suppliers, distributors and other organizations (Jiantong et al., 2016), and being able to speculate and prevent their demand is a key point for companies' success.

The remainder of the paper is as follows: in section 2 the methodology is described; section 3 provides a general background on the structure of the ANNs; section 4 presents the two models developed, followed by section 5 where results are proposed. Implications and conclusions are finally provided in section 6 .

\section{METHODOLOGY}

The framework proposed by Bottani et al. (2019) has been taken as guideline for the construction of the two networks, properly modified when necessary. The procedure is below depicted (Figure 1) and summarized.

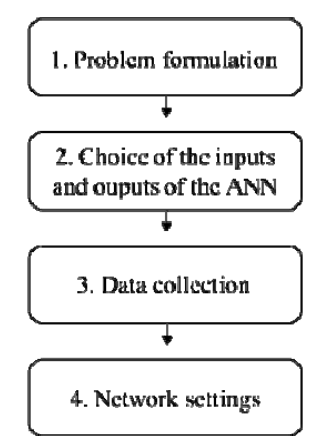

Figure 1 - Adapted framework by Bottani et al., (2019) for the development of an ANN.

1. Problem formulation: the context in question has been analyzed together with the management of Company $\mathrm{A}$, as well as the problem to be faced and the inputs of the ANN which influence the requested output results;

2. Choice of the inputs and outputs of the ANN: once the main inputs were identified in step 1, the relevant ones were further selected;

3. Data collection: three-monthly data from 2013 to 2018 were made available directly from Company A, thanks to meetings and interviews, considering as fiscal year the period 1st July30th June;

4. Network setting: definition of the structure of the network.

In the original framework by Bottani et al., the fourth step was further divided into three sub-steps, namely the identification of the network training algorithm, the transfer function and the termination criterion, and followed by two additional steps, namely the choice of the hidden neurons and layers, and the parameter settings with the final choice of the best ANN configuration: in this case these sub-steps are redundant since an automatic architecture selection by SPSS was set, which already has default settings.

Once the networks were defined, the ANNs were trained with historical data and then tested.

\section{BACKGROUND ON THE ARTIFICIAL NEURAL NETWORK STRUCTURE}

A neural network has at least two physical components: the processing elements (i.e. neurons) and the connections between them (i.e. links, having a weight parameter associated) (Zhang and Gupta, 2000). Each neuron receives stimuli from the neighboring neurons connected to it, and after processing the information produces outputs. Many configurations are possible; in the following we will refer to the most popular type of neural network, namely the Multilayer Perceptron (MLP), consisting of at least three layers of nodes: an input layer, a hidden layer and an output layer. Input neurons are those receiving stimuli from outside the network; hidden neurons, conversely, capture signals from other neurons, and analogously transmit a signal to 
other neurons; these last are the output neurons. This structure is known as feedforward architecture, because the information flow starts from input neurons and flows forward to the output layers without any loop.

Each received input is multiplied by the corresponding weight parameter and results are added in order to produce a weighted sum, which passes through an activation function to produce the final output of the neuron.

Figure 2 below outlines the general MLP structure.

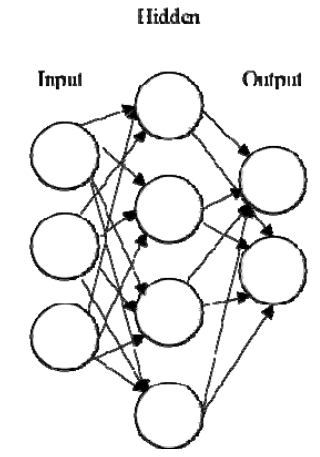

Figure 2 - Structure of a Multilayer Perceptron.

Specifically, the key elements to be defined for the development of an ANN are the following: dependent (i.e. output neurons) and independent (i.e. input neurons) variables; number of hidden layers and their relative activation function linking the weighted sums of units in a layer to the values of units in the succeeding layer, and the number of units in each hidden layer; the output layer with its activation function and the eventual method of rescaling the dependent variables; the measure of the error; the type of training and the optimization algorithm used to estimate the weights, together with the stopping rule determining whether the training should stop or not. Last but not least, the partition dataset has to be set, necessary to divide the available data respectively into training, testing and holdout samples.

\section{DEVELOPMENT OF THE ARTIFICIAL NEURAL NETWORKS}

\subsection{Input and output selection}

The aim of the tool is to predict the demand of the following seven car components whose impact in terms of revenue is relevant for Company A: nose, front spoiler, machine structure, arms, brake discs, upright and bearings. Note that some components can be "right" or "left", "upper" or "lower"; accordingly, the final number of components analyzed is eighteen.

Starting from these desired outputs, the key factors affecting the demands were identified as well; as a result, the following seven elements have been considered as inputs:

1. Component category, as many items can be grouped into a main class;
2. Championship to which sales data are related, since different championships correspond to different climatic conditions and cultural factors, which may affect accidents or spare parts demand;

3. Number of machines competing in each championship, which can also change from year to year;

4. Number of races of each championship, which can vary as well from year to year;

5. Ageing, simply attributable as YES or NO depending on the component;

6. Car life cycle, namely first year of life, interim period and last year of life;

7. Trimester, namely July-September, OctoberDecember, January-March, April-June. Note that this input was considered only in the first model, as in the second one the partitioning variable imposes a data partitioning in accordance with the reference year, regardless of the trimester.

\subsection{Architecture of the models}

The automatic architecture selection by SPSS was chosen, procedure which automatically builds the best ANN configuration and includes default settings.

The demand value of the eighteen items corresponds to the dependent variable, while the seven previously mentioned inputs to the independent variables.

In this case, the automatic selection allows only one hidden layer by default, activated by the hyperbolic tangent. Even as far as the activation function for the output layer (containing the dependent variable) the automatic selection led to the only choice of the identity function. The rescaling of scale dependent variables was set as standardized; the error as the sum-of-squares.

Once these key points were fixed, it is the turn of the training. The online training has been selected, mostly used when big data are available; according to SPSS, when this type of training is involved, the optimization algorithm through which the synaptic weight are identified necessarily is the gradient descendent.

The training stops when, after a specified number of steps, there is no decrease in error.

The difference between the two models comes from the breakdown of data for the training-testing-holdout phases. Indeed, SPSS offers the opportunity to choose from two ways, both investigated: to randomly assign percentages (Model 1) or to use a partitioning variable (Model 2). The holdout step is considered only in the first model as the partitioning variable, by attributing value 0 or 1 , only divides data in two main groups, namely training and testing.

Table 1 below summarizes the main characteristics of the models. 
Table 1: Settings of the models.

\begin{tabular}{|c|c|c|}
\hline \multicolumn{2}{|c|}{ DEPENDENT VARIABLES } & $\begin{array}{l}\text { Demand of } \\
\text { the } 18 \text { car } \\
\text { components }\end{array}$ \\
\hline \multicolumn{2}{|c|}{ INDEPENDENT VARIABLES } & $\begin{array}{l}7 \text { input } \\
\text { factors }\end{array}$ \\
\hline \multirow{3}{*}{$\begin{array}{l}\text { HIDDEN } \\
\text { LAYERS }\end{array}$} & $\begin{array}{l}\text { Hidden Layers } \\
\text { Number }\end{array}$ & 1 \\
\hline & $\begin{array}{l}\text { Units in the } \\
\text { Hidden Layers }\end{array}$ & 9 \\
\hline & $\begin{array}{l}\text { Activation } \\
\text { Function }\end{array}$ & $\begin{array}{c}\text { Hyperbolic } \\
\text { Tangent }\end{array}$ \\
\hline \multirow{4}{*}{$\begin{array}{l}\text { OUTPUT } \\
\text { LAYERS }\end{array}$} & Number of Units & 1 \\
\hline & $\begin{array}{c}\text { Rescaling of } \\
\text { Scale Dependent } \\
\text { Variables }\end{array}$ & Standardized \\
\hline & $\begin{array}{l}\text { Activation } \\
\text { Function }\end{array}$ & Identity \\
\hline & Error Function & $\begin{array}{l}\text { Sum-of- } \\
\text { Squares }\end{array}$ \\
\hline \multirow[b]{2}{*}{ TRAINING } & Type & Online \\
\hline & $\begin{array}{l}\text { Activation } \\
\text { Function }\end{array}$ & $\begin{array}{l}\text { Gradient } \\
\text { Descent }\end{array}$ \\
\hline \multirow{2}{*}{$\begin{array}{c}\text { PARTITIO- } \\
\text { NING }\end{array}$} & MODEL 1 & $\begin{array}{c}\text { Pre-fixed } \\
\text { Percentages }\end{array}$ \\
\hline & MODEL 2 & $\begin{array}{c}\text { Partitioning } \\
\text { Variable }\end{array}$ \\
\hline
\end{tabular}

Table 2, instead, shows the exact subdivision of historical data into the three phases.

Specifically, the partitioning variable used in model 2 imposes that data until 2017 are involved in the training phase, while from 2018 onwards for tests. Note that no outlier or missed values were found, probably due to the niche market in which Company A operates.

Table 2: Historical data subdivision into training, testing and holdout phases; in brackets the percentage.

\begin{tabular}{|c|c|c|}
\hline & MODEL 1 & MODEL 2 \\
\hline $\begin{array}{c}\text { TRAINING } \\
\text { PHASE }\end{array}$ & $2.341(80.6 \%)$ & $2.660(91.6 \%)$ \\
\hline $\begin{array}{c}\text { TESTING } \\
\text { PHASE }\end{array}$ & $282(9.7 \%)$ & $245(8.4 \%)$ \\
\hline $\begin{array}{c}\text { HOLDOUT } \\
\text { PHASE }\end{array}$ & $282(9.7 \%)$ & - \\
\hline TOTAL & $2.905(100 \%)$ & $2.905(100 \%)$ \\
\hline
\end{tabular}

\section{RESULTS}

Table 3 below shows the relative errors resulting during first the training phase, then the testing and holdout respectively for Model 1 and Model 2.
Table 3: Relative errors resulting from the two models of ANN.

\begin{tabular}{|c|c|c|}
\hline & MODEL 1 & MODEL 2 \\
\hline & \multicolumn{2}{|c|}{ RELATIVE ERROR (\%) } \\
\hline $\begin{array}{c}\text { TRAINING } \\
\text { PHASE }\end{array}$ & 53.7 & 49.7 \\
\hline $\begin{array}{c}\text { TESTING } \\
\text { PHASE }\end{array}$ & 35.9 & 51.5 \\
\hline $\begin{array}{c}\text { HOLDOUT } \\
\text { PHASE }\end{array}$ & 41.1 & - \\
\hline
\end{tabular}

As can be seen, two opposite situations occur: in Model 1 , the testing phase successfully returns a relative error lower than the training phase, while in Model 2 after the training the error increases a bit. According to that, we can argue that Model 1, namely the one in which data were partitioned according to pre-fixed percentages, is more reliable and accurate.

Furthermore, by deepening results, an analysis on the impact of each independent variable was carried out; outcomes are below depicted in percentages (Table 4 for Model 1 and Table 5 for Model 2).

Note that the normalized value is obtained by dividing the impact value itself of each item for the maximum value identified (e.g. for Model 1, the impact of the component category, namely 25.3).

Table 4: Percentages of inputs' effects on outputs for Model 1.

\begin{tabular}{|c|c|c|}
\hline & \multicolumn{2}{|c|}{ MODEL 1 } \\
\hline & IMPACT & $\begin{array}{c}\text { NORMALIZED } \\
\text { IMPACT }\end{array}$ \\
\hline $\begin{array}{c}\text { Component } \\
\text { Category }\end{array}$ & 25.3 & 100 \\
\hline Championship & 14.9 & 58.9 \\
\hline $\begin{array}{c}\text { Number of } \\
\text { Machines }\end{array}$ & 6.6 & 26.3 \\
\hline $\begin{array}{c}\text { Number of } \\
\text { Races }\end{array}$ & 13.0 & 51.6 \\
\hline Ageing & 23.5 & 92.7 \\
\hline Car Life Cycle & 3.2 & 12.5 \\
\hline Trimester & 13.5 & 53.5 \\
\hline
\end{tabular}


Table 5: Percentages of inputs' effects on outputs for Model 2.

\begin{tabular}{|c|c|c|}
\hline & \multicolumn{2}{|c|}{ MODEL 2 } \\
\hline & IMPACT & $\begin{array}{c}\text { NORMALIZED } \\
\text { IMPACT }\end{array}$ \\
\hline $\begin{array}{c}\text { Component } \\
\text { Category }\end{array}$ & 28.9 & 100 \\
\hline Championship & 21.0 & 72.6 \\
\hline $\begin{array}{c}\text { Number of } \\
\text { Machines }\end{array}$ & 4.9 & 16.8 \\
\hline $\begin{array}{c}\text { Number of } \\
\text { Races }\end{array}$ & 26.5 & 91.9 \\
\hline Ageing & 14.0 & 48.4 \\
\hline Car Life Cycle & 4.7 & 16.6 \\
\hline
\end{tabular}

By modifying the allocation of historical data, the relative importance of the different impact changes. In both cases, the component category is the item affecting the most the output, followed by, respectively, the ageing for Model 1, and the number of races for Model 2 which, conversely, is not relevant in the first model. The life cycle, instead, turns out to have a low effect on both results.

\section{CONCLUSIONS}

This paper aimed at presenting two models of artificial neural networks developed in Statistical Package for Social Sciences for the demand forecasting of car components for a company operating in the automotive sector in the North of Italy. The automatic architecture selection was set for both models, including default settings of parameters; accordingly, the two models are similar, differing only for the data allocation into training, testing and holdout phases.

Eighteen car components were analyzed.

Overall, the models were proved to be successful, and can be an effective support for management in their operational decisions and production planning.

Specifically, Model 1, retuning a significant reduction of the relative error during the testing phase, turned out to be the best configuration among the two.

The study contributes in deepening the applications of ANNs in the field of demand forecasting, demonstrating once again the great potential of the tool as a promising alternative approach to traditional linear methods.

For sure, further insights can be considered. For instance, other tools can be tested with the same dataset in order to compare results; more ANNs models can be developed, e.g. by combining the component category, which turned out to be the most impactful input, or by taking into account a different timespan (e.g. annual data). Furthermore, considering applying also genetic programming techniques and benchmark the two approaches would be interesting.

Models can also be implemented in fields other than the automotive, by taking into account different products or components.

\section{REFERENCES}

Bottani E., Centobelli P., Gallo M., Kaviani M. A., Jain V., Murino T., 2019. Modelling wholesale distribution operations: an artificial intelligence framework. Industrial Management and Data Systems, 119 (4), 698-718.

Croxton K. L., Lambert D. M., García-Dastugue S. J., Rogers D. S., 2002. The demand management process. The International Journal of Logistics Management, 13 (2), 51-66.

Fradinata E., Suthummanon S., Sirivongpaisal N., Suntiamorntut W., 2014. ANN, ARIMA and MA timeseries model for forecasting in cement manufacturing industry. International Conference of Advanced Informatics: Concept, Theory and Applications (ICAICTA), 39-44. September 2022, Yogyakarta (Indonesia).

González Vergas C.A., Cortés M.E., 2017. Automobile spare-parts forecasting: A comparative study of time series methods. International Journal of Automotive and Mechanical Engineering, 14 (1), 3898-3912.

Hamzaçebi C., Avni Es H., Çakmak R., 2017. Forecasting of Turkey's monthly electricity demand by seasonal artificial neural network. Neural Computing and Applications, 1-15.

Jiang B., Tian L., Xu Y., Zhang F., 2016. To share or not to share: Demand forecast sharing in a distribution channel. Marketing Science, 35 (5), 800-809.

Jiantong Z., Zhuoqi G., Xiaodong C., 2016. Evaluation of automotive supply chain risks: An empirical research. 13th International Conference on Service Systems and Service Management (ICSSSM). June 24-26, Kunming (China).

Laosiritaworn W.S., 2011. Supply chain forecasting model using computational intelligence techniques. Chiang Mai University Journal of Natural Sciences, 10 (1), 19-28.

Myerholtz B., Caffrey H., 2014. Demand Forecasting The key to better supply-chain performance. Available from: imagesrc.bcg.com/Images/Demand_Forecasting_Oct_20 14 tcm9-81416.pdf

Shahrabi J., Mousavi S.S., Heydar M., 2009. Supply chain demand forecasting: a comparison of machine learning techniques and traditional methods. Journal of Applied Sciences, 9 (3), 521 527.

Yucesan M., Gul M., Celik E., 2017. Application of Artificial Neural Networks using Bayesian training rule in sales forecasting for furniture industry. Drvna Industrija, 68 (3), 219-228.

Zhang G., Patuwo B.E., Hu M.Y., 1998. Forecasting with artificial neural networks: The state of art. International Journal of Forecasting, 14, 35-62.

Zhang Q.J., Gupta K.C., 2000. Neural Network Structure. In: Artech House, eds. Neural Network for RF and Microwave Design. Norwood, MA, USA, 61-103. 


\begin{abstract}
AUTHORS' BIOGRAPHY
Letizia TEBALDI is a first year Ph.D. student in Industrial Engineering at the Department of Engineering and Architecture of the University of Parma. She graduated cum laude in March 2018 in Management Engineering, presenting a dissertation on a systematic literature review on sustainable supply chain and innovation. Her research interests are mainly on logistics and supply chain management; sustainable supply chain; analysis and optimization of supply chain; industry4.0 for operators' safety.
\end{abstract}

Sara PINDARI graduated in Management Engineering in March 2019 at the University of Parma. She is actually working in Company A in the Sales Operation area.

Eleonora BOTTANI is Associate professor in Mechanical Industrial Plants at the Department of Engineering and Architecture of the University of Parma. She graduated (with distinction) in Industrial Engineering and Management in 2002, and got her Ph.D. in Industrial Engineering in 2006, both at the University of Parma. Her research activities concern logistics and supply chain management issues. She is author (or co-author) of more than 170 scientific papers, referee for more than 60 international journals, editorial board member of five scientific journals, Associate Editor for one of those journals, and editor-in-chief of a scientific journal. 